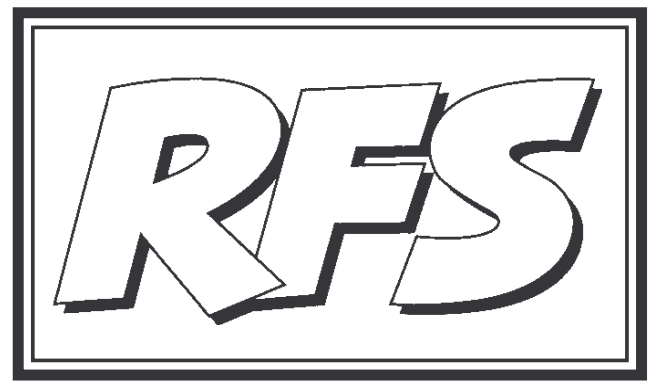

Revista de Fomento Social, 61 (2006), 647-665

\title{
El debate de la laicidad en España: tres textos
}

El 4 de diciembre, con motivo de la fiesta de la Constitución, la Secretaría de libertades públicas, cuyo titular es Álvaro Cuesta, de la Comisión ejecutiva federal del PSOE hizo público un documento, titulado Constitución, Laicidad y Educación para la Ciudadanía, interesante para el debate sobre la laicidad en España. A los pocos días, el arzobispo de Pamplona y Tudela, Fernando Sebastián Aguilar, ofrecía unas densas y matizadas reflexiones sobre ese documento, Lectura crítica del Manifiesto del PSOE, partido cuyo secretario de organización había dicho que, aún siendo del partido, el texto no reflejaba todas las opiniones y sensibilidades del mismo; una muestra representativa de esto último es el tercer texto que publicamos, Pacto por una laicidad incluyente, aprobado por "Cristianos Socialistas" del PSOE, cuyo responsable federal es Carlos García de Andoin. El 23 de noviembre, unos días antes del documento del PSOE, la Conferencia Episcopal Española hizo pública una instrucción pastoral, que había sido objeto de una larga y, al parecer, debatida elaboración: Orientaciones morales ante la situación actual de España, texto que conoció una mayor difusión y, por ello, no reproducimos, pero que podría leerse contextualmente junto con los otros tres que publicamos. Con la difusión de estos tres documentos, Revista de Fomento Social pretende aportar unos elementos para un diálogo sobre la laicidad, que sigue vivo y abierto en la sociedad española. 


\section{Declaración de laSecretaría de Lbertades Públicas de la Comisión Ejecutiva del PSOE, con motivo del XXVIII aniversario de la Constitución ${ }^{1}$}

\section{Constitución, Laicidad y Educación para la Ciudadanía}

Málaga, 4 de diciembre de 2006.

(1) En el año 2006 España conmemora el XXVIII Aniversario de la Constitución de 1978 que, junto a la Constituci ón de 1931, representa la más alta plasmación en la historia del pueblo español de su voluntad de vivir en un régimen democrático. Se trata, como cada a ño, de un acontecimiento que debe llenar de orgullo y satisfacción a los españoles pues, no en vano, tras la quiebra del régimen republicano y con él, de la legitimidad democrática, el vivido desde la promulgación de la Constitución del 78 , ha sido el único período constitucional de normalidad democrática y estabilidad política.

(2) La nuestra es una Norma Fundamental cuya elaboraci ón estuvo presidida por la voluntad de consenso, concordia y generosidad de todas las fuerzas políticas llamadas a representar a los ciudadanos en el a ño 1977 y, en cuya aprobación, jugó un papel esencial el entusiasmo de un pueblo, el español, ávido de libertad y democracia.

(3) La Constitución de 1978 es una norma lásica que garantiza el ejercicio en igualdad del amplio cat álogo de derechos y libertades atribuido a los ciudadanos y que diseña un marco para la convivencia en paz asegurando la cohesión y la estabilidad política, social y económica del país.

(4) Como pone de manifiesto el actual proceso de renovacín de nuestro Estado autonómico, en dicho marco de convivencia diseñado por la Norma Fundamental espãola tiene cabida la articulacón de la diversidad territorial que caracteriza a la Espana plural. Pero, además de dicha diversidad territo rial, nuestra Norma básica sienta las bases para el desarrollo de otro tipo de diversidad: el que deriva del libre y plural ejercicio del derecho de libertad de conciencia de todos sus ciudadanos. En un momento como el actual, en el que el fenómeno migratorio está convirtiendo a la sociedad espãola en una sociedad multicultural, es preciso recordar y reafirmar el valor de un principio constitucional, el de Laicidad, cuya vigencia es esencial para que nos hallemos en grado de revalidar los ya veintiochõ@s de convivencia en libertad que han conducido a España a un estatus de progreso y estabilidad sin precedentes.

\footnotetext{
${ }^{1}$ Los números marginales de los documentos I y III son de la redacción; los del documento II son del original.
} 
Y ello porque la Laicidad se configura como un marco ioneo y una garantía de la libertad de conciencia donde tienen cabida todas las personas con inde pendencia de sus ideas, creencias o convicciones y de su condióni personal o social, siendo por ellorequisito para la libertad y la igualdad

(5) Los fundamentalismos monote ístas o religiosos siembran fronteras entre los ciudadanos. La laicidad es el espacio de Integraci ón. Sin laicidad no habría nuevos derechos de ciudadan ía, ser ían delitos civiles algunas libertades como la interrupci ón voluntaria del embarazo, el matrimonio entre personas del mismo sexo,... y dejarían de ser delitos el maltrato a la mujer, la ablación o la discriminación por razón de sexo. Sin laicidad ser ía difícil evitar la proliferación de conductas nada acordes con la formacón de conciencias libres y críticas y con el cultivo de las virtudes cívicas.

(6) Desde la laicidad se garantiza la convivencia de culturas, ideas y religiones sin subordinaciones ni preeminencia de creencias, sin imposiciones, sin mediatizar la voluntad ciudadana, sin subordinar la acçin política de las Instituciones del Estado Social y Democrático de Derecho a ningún credo o jerarquía religiosa. La Laicidad es garantía para desarrollar los derechos de ciudadanía ya que el Estado Democrático y la Ley, aś como la soberanía, no obedecen a ningún orden preestablecido de rango superior, pues la única voluntad y soberanía es la de la ciudadanía.

(7) Creemos que el respeto a todas las opciones que suscita la vida perso nal y social, el respeto de la discrepancia y de la diferencia y la apreciación de la riqueza de la diversidad de concepciones y valoraciones son pilares esenciales del entendimiento democrático. Sin embargo, el cultivo del dere cho de libertad de conciencia y la autonom ía moral, ideológica o religiosa de los individuos, debe conciliarse con la potenciaci ón del mínimo común ético constitucionalmente consagrado integrado por el conjunto de valores que constituyen las señas de identidad del Estado Social y Democrático de Derecho: igualdad, libertad, justicia, pluralismo, dignidad de la persona y derechos fundamentales.

(8) En una sociedad cada vez nás plural en la que se hallan en circulacôn pluralidad de c ódigos éticos, fruto, entre otros factores, de la generaliza ción de los movimientos migratorios, uno de los desafíos más importantes que se plantean a los poderes $\mathrm{p}$ úblicos tras veintiocho a ños de vigencia constitucional, es contribuir a la formación de "conciencias libres, activas y comprometidas" con el "mínimo común ético constitucional", esto es, con el patrimonio común de valores constitucionalmente consagrado. 
(9) Y es en dicho marco donde el legislador democr ático ha asumido la parte de responsabilidad que le corresponde incluyendo en la nueva Ley Orgánica 2/2006, de 3 de mayo, de Educaci ón, la asignatura Educación para la Ciudadan ía y los Derechos Humanos , una materia que trata de dar cumplimiento al mandato constitucional de promocionar los valores que integran lo que el ilustre constitucionalista Francisco Tomás y Valiente dio en llamar "ideario educativo constitucional" recogido en el artículo 27.2 de la Norma Suprema. La Constitución española del 78 no diseña una enseñanza valorativamente neutral sino que hace pivotar el sistema educativo sobre el deber de trasmitir y promocionar el respeto a los principios democr áticos de convivencia y a los derechos y libertades fundamentales como el modo más adecuado para consolidar y perpetuar la vigencia del propio $r$ égimen constitucional y la convivencia de todos.

(10) En el vig ésimo octavo aniversario de la Constituci ón española de 1978 , los socialistas queremos manifestar nuestro compromiso con el fo mento inobjetable de laciudadanía como eje de la democraciay por ello nos congratulamos de la creación de una nueva materia curricular que no hará sino fortalecer dicho valor.

\section{Fernando Sebastián Aguilar}

\section{Lectura crítica del Manifiesto del PSOE Constitución, Laicidad y Educa- ción para la Ciudadanía}

Pamplona, 10 de diciembre de 2006

1. Conviene reconocer desde el principio que es bueno poder contar con textos como éste, en el que aparece manifiestamente el pensamiento de quienes tienen especial responsabilidad en la vida pública. Esta es la forma de poner en claro las ideas de cada uno y de facilitar un debate público, serio y objetivo.

$2^{\mathbf{o}}$. El Manifiesto organiza su argumentación en torno al concepto de laicidad. Lo primero que llama la atención es que a lo largo del texto no se encuentra ninguna definición de este concepto. La lectura atenta del mismo deja la impresión de que se confunde laicidad con laicismo. En todo caso, para avanzar en el diálogo tendríamos que ponernos de acuerdo en el signi ficado de cada una de estas dos palabras. Para los católicos, normalmente, laicidad del Estado y de las instituciones políticas significaneutralidad ante las diferentes preferencias religiosas de los ciudadanos. El Estado reconoce 
el derecho a la libertad religiosa de los ciudadanos y favorece su ejercicio, sin hacer suya ninguna religión en concreto ni discriminar a ningún grupo por razones religiosas. Entendida así, laicidad equivale a lo que podríamos llamar neutralidad religiosa positiva. Este concepto de laicidad ha sido ex presamente aceptado por el magisterio reciente de la Iglesia y forma parte de la visión de la democracia hoy dominante en los ambientes católicos. En cambio, cuando hablamos de laicismo entendemos aquella actitud por la que el Estado no reconoce la vida religiosa de los ciudadanos como un bien positivo que forma parte del bien común de los ciudadanos, que debe ser protegido por los poderes públicos, sino que la considera más bien como una actividad peligrosa para la convivencia, que debe por tanto ser ignorada, marginada y aun políticamente reprimida.

$3^{\mathbf{o}}$. Si estos conceptos se aclarasen, podríamos estar de acuerdo en que la laicidad, rectamente entendida y ejercida, es garantía de libertad, igualdad y convivencia. La confusión de conceptos aparece cuando se recurre a un "mínimo común ético constitucionalmente consagrado", que se presenta como fruto de la voluntad y soberanía de la ciudadanía, al que se atribuye un valor supremo y definitivo, sin sujeción a "ningún orden preestablecido de rango superior". Lo sorprendente es que, cuando se quiere describir este "mínimo común ético", no se hace a partir del texto constitucional ni de las convicciones o ideales morales de los ciudadanos que, en ejercicio de su soberanía, lo elaboraron, aprobaron y promulgaron, sino que es presentado en nombre de una concepción ideológica y laicista sobreañadida al texto constitucional e impuesta gratuitamente al conjunto de la población.

$4^{\mathbf{o}}$. A mi juicio, el defecto del raciocinio aparece cuando se intenta explicar la visión de conjunto. Los autores del Manifiesto quieren resolver el problema que la pluralidad cultural de los ciudadanos puede suponer para la convi vencia. No hay duda de que es un fin bueno e importante. El error está en que, en vez de entender el ejercicio de la autoridad como un servicio al bien común de los ciudadanos, incluido el ejercicio de la libertad religiosa según sus convicciones religiosas y morales, se da por supuesto que las religiones no pueden proporcionar un conjunto de convicciones morales comunes capaces de fundamentar la convivencia en la pluralidad, sino que son más bien fuente de intolerancia y de dificultades para la pacífica convivencia. Por lo cual, para evitar los conflictos previsibles, es preciso recluirlas a la vida privada y sustituirlas en el orden de lo social y de lo público por un conjunto de valores denominados "señas de identidad del Estado Social y de Derecho Democrático", sin referencia religiosa alguna, impuestos desde 
el poder político, a los que se concede el valor de última referencia moral en la vida pública. En este contexto, descartadas las convicciones religiosas y morales de los ciudadanos como inspiradoras de la convivencia, corresponde al poder político configurar la nueva conciencia de los ciudadanos en susti tución de su conciencia religiosa y moral, por lo menos en lo concerniente a la vida social y política.

$5^{\mathbf{0}}$. En esta manera de razonar se oculta una visión empobrecida y desfigurada de la religión. Se da por supuesto que la conciencia moral fundada en la religión no es capaz de fomentar la convivencia en la pluralidad, por lo que la diferencia de religiones se ve como un peligro para la convivencia democrática. El Manifiesto dice: "Los fundamentalismos monoteístas y religio sos siembran fronteras entre los ciudadanos". ¿Se quiere decir con ello que los monoteísmos y las religiones en general son siempre fundamentalistas? Porque si fuera de otro modo no valdría el argumento. Nosotros pensamos que, al menos en lo que se refiere a la religión cristiana y católica, esta manera de ver las cosas no responde a la realidad y resulta objetivamente ofensiva. Fe cristiana y fundamentalismo son dos cosas distintas. Más todavía, cual quier religión, vivida auténticamente, no es fundamentalista. Porque Dios no es fundamentalista. El fundamentalismo implica intolerancia, se vista de monoteísmo o de laicismo. Los católicos entendemos las cosas de otra ma nera. Basta leer algunos documentos del Concilio Vaticano II, algún resumen reciente de la Doctrina Social de la Iglesia o los documentos pertinentes de la Conferencia Episcopal Española. En el proceso político la realidad original son los ciudadanos, como sujetos libres, a la vez personales y sociales. Son ellos quienes libremente y según su manera de entender las cosas, se dan unas normas para regular su convivencia. Ellos construyen un sistema de convivencia según sus propias convicciones, culturales, religiosas, sociales y morales, como fruto de su voluntad de convivencia, que queda garantizada por las leyes y en último término por la conciencia moral de los ciudadanos y de los gobernantes. En consecuencia, quienes administran los bienes comunes y protegen el bien común de la convivencia tienen que interpretar los textos jurídicos y ejercer el poder de acuerdo con los textos aprobados, y en último término con las convicciones y los intereses de los ciudadanos que organizaron la convivencia para el bien de todos. No hay ninguna necesidad de que los poderes políticos impongan otro código moral ideológico, ajeno a los ciudadanos, por lo menos a buena parte de ellos, en sustitución de sus convicciones religiosas y morales, puesto que son estas mismas convicciones las que respaldan y garantizan el sentido vinculante de las normas comunes 
de convivencia. Quien conozca de cerca la versión actual de la moral social de la Iglesia, verá fácilmente que los cristianos no necesitamos prescindir de nuestra fe y nuestros criterios morales para tener un sentido tolerante y democrático de la convivencia. La proyección del amor al prójimo, norma suprema de nuestra conducta moral, al campo de las realidades políticas, es base suficiente y firme para fundamentar las necesarias actitudes de justicia, tolerancia y solidaridad. La dimensión social y política de la fe y de la caridad es esencial para nosotros. La fe en Dios descubre unas dimensiones nuevas de la vida personal y suscita un ideal de vida que abarca la totalidad de la vida personal, en su realidad más íntima, en las relaciones interpersonales y en toda clase de actuaciones. Es más, la veracidad del amor a Dios se comprueba por la sinceridad y efectividad del amor al prójimo.

$\mathbf{6}^{\mathbf{0}}$. Esta proyección social y política de la fe y de la caridad es capaz de sustentar un orden democrático de convivencia en una sociedad libre y pluralista, con tal de que las religiones, asumidas libremente por los ciudadanos, adopten entre sí una posición respetuosa y tolerante y sean capaces de ampliar estas mismas actitudes hacia los sectores laicos no religiosos. Así es como nos situamos los cristianos. Por eso no podemos aceptar como justo el intento de recluir nuestras convicciones religiosas al ámbito de la vida privada, para imponernos como base y condición para la convivencia democrática unos valores y una interpretación de los textos constitucionales que eliminan nuestra visión religiosa de la vida y la manera de entender el bien común de quienes formamos parte de la sociedad. La convivencia en una sociedad religiosa y culturalmente plural no necesita un apoyo exterior a las religiones, impuesto autoritariamente desde fuera; basta con que los ciudadanos encuentren en sus respectivas conciencias religiosas fundamentos eficaces para el respeto a la libertad de los demás, actitudes claras y abiertas de tolerancia y colaboración. Según esta manera de ver las cosas, la laicidad del Estado consistirá en que el poder político respete y favorezca por igual el desarrollo de cada religión y de la visión laica de la vida, de forma proper cionada a su implantación y significación social, sin discriminar ni privilegiar a ninguna de ellas, dejando que cada grupo viva tranquilo según sus propias convicciones y valores. Si hay dificultades para fundamentar la convivencia, los poderes políticos tendrán que exigir a los líderes y responsables de cada grupo el desarrollo de esta conciencia de convivencia y tolerancia entre sus miembros. Lógicamente esto supone que tanto los ciudadanos religiosos como los laicos quieran convivir pacíficamente, supone también que las religiones sean capaces de desarrollar unos criterios morales capaces de fundamentar 
la convivencia con otras religiones y con los que no tienen ninguna religión. Como requiere también que los laicos reconozcan a la religión en general, y a cada una de las religiones presentes, como elementos positivos de la con vivencia, sin alimentar sospechas ni reticencias respecto de su capacidad de fundamentar un comportamiento tolerante y democrático. Desde el año 1971 la Iglesia española ha seguido en este punto un itinerario intachable. Si en la nueva situación de pluralismo religioso incipiente, favorecido por el crecimiento de la inmigración en estos últimos años, aparecen dificultades, tendremos que hacer todos, autóctonos y recién llegados, un esfuerzo de adaptación a la nueva situación.

$7^{\mathbf{0}}$. Es posible que los autores del Manifiesto piensen de otra manera y tengan la convicción de que las ideas religiosas son incapaces de fundamentar un comportamiento social aceptable. Tal manera de pensar se manifiesta cuando dicen, por ejemplo, que sin la laicidad no hubieran podido ser consideradas como delitos algunas prácticas rechazables, como la ablación o la violencia familiar. Así se explica también que el texto entienda el concepto de laicidad como un verdadero laicismo, que no se conforma con la neutralidad religiosa del Estado, sino que lleva a desplazar las ideas religiosas y sustituirlas por otros valores sin referencia religiosa alguna. Estos valores, entendidos de manera absoluta, sin referencia a un orden moral objetivo, pueden ser interpretados como convenga en cada caso, hasta reconocer como verdaderos derechos algunas prácticas incompatibles con principios morales fundados en la recta razón y recogidos en la Constitución, tal es el caso, p.e., de la legitimación del aborto, la producción y destrucción de embriones humanos con fines interesados, el reconocimiento de los pactos de convivencia entre personas del mismo sexo como verdadero matrimonio, etc. Tales cosas no son fruto de la laicidad sino de la supresión de criterios verdaderamente morales en el ordenamiento de la vida pública y en el ejercicio de la autoridad. El futuro no está en un laicismo obligatorio, sino en el diálogo honesto y sincero de las religiones entre sí y con los sectores laicos.

$\mathbf{8}^{\mathbf{o}}$. El protagonismo reconocido en el Manifiesto a los valores laicos de ciudadanía y convivencia, no solamente desplaza la influencia ética de las religiones, sino que se impone incluso sobre el sentido más obvio del texto constitucional. Varias expresiones del Manifiesto hacen pensar que sus autores argumentan más desde una ideología laicista, previa al texto constitucional, que a partir del texto objetivo de la Constitución de 1978. De otro modo no se explica la innecesaria equiparación de la Constitución de 1931 con la de 1978 como muestra de la "más alta plasmación" de la vida democrática del 
pueblo español. Da la impresión de que se quiere presentar la Constitución de 1931 como complemento y referencia interpretativa de la Constitución actualmente vigente. ¿Es que el ejercicio de la soberanía de la nación espa ñola que sustenta el texto constitucional de 1978 no fue suficiente? ¿No fue, al menos, tan pleno y eficaz como el de 1931? En el Manifiesto se presenta la laicidad como un principio esencial de la Constitución actual, pero este término no aparece en el texto constitucional, aunque sí esté presente esta idea con expresiones equivalentes. Se pretende definir las relaciones de las instituciones políticas con las religiones y con la Iglesia católica sin hacer la menor referencia al art. 16 de la Constitución vigente. Y se quiere también describir la naturaleza y la función social de la educación sin tener en cuenta ni aludir siquiera al art. 27 de nuestra Constitución.

$\mathbf{9}^{\mathbf{0}}$. Finalmente, el ritmo y la estructura del texto hacen pensar que está elaborado para justificar la existencia y la imposición de la nueva asignatura "Educación para ciudadanía". Se dice que los poderes políticos tienen que contribuir a formar las conciencias de acuerdo con el "mínimo común ético constitucional". Reconocer al poder político como legítimo formador de las conciencias de los ciudadanos puede ser una afirmación peligrosa. El recur so a ese mínimo ético constitucional implica algo que no se dice, que es la facultad de interpretar el sentido de esos principios éticos que se reconoce al poder político. Sin respetar los principios morales de los ciudadanos, ni siquiera el sentido evidente del texto constitucional. En cambio, una visión verdaderamente democrática de la cuestión obliga al poder político a respe tar las convicciones religiosas y morales de los ciudadanos sin obligarnos a someter nuestra conciencia a los criterios o a las opiniones personales de los gobernantes. El texto afirma que el sistema educativo constitucional no prevé una "educación neutral", sino que intenta "trasmitir y promocionar" el respeto a los principios democráticos de convivencia y a los derechos y libertades necesarios para consolidar el régimen constitucional y la convi vencia de todos. Contra esta manera de pensar decimos que "los principios democráticos de convivencia" nacen de las convicciones morales de los ciudadanos que inspiraron el texto de la Constitución. En consecuencia, estos principios sobre los que se apoya la convivencia no pueden ser interpretados por el poder político desde otros principios añadidos y sobrepuestos al texto constitucional, sino que deben ser interpretados respetando las convicciones religiosas y morales de los ciudadanos y la consecuente y primaria responsabilidad educativa de los padres (arts. 16, 27.2 y 27.6). En consonancia con esto hay que decir que la Constitución de 1978 no tiene por 
qué ser interpretada desde la de 1931. Ésta sí era laica, y laicista. La actual no. Al final del recorrido se ve el valor esencial que en los proyectos del gobierno tiene la asignatura de "Educación para la ciudadanía". Si las religiones no son capaces de fundamentar la convivencia "porque siembran fronteras entre los ciudadanos", el gobierno tiene que mentalizar a las nuevas generaciones con otros principios morales no religiosos "para consolidar y perpetuar la vigencia del propio régimen constitucional y la convivencia de todos". Uno no puede menos de preguntarse si esta manera de entender las cosas puede tener cabida en una mentalidad verdaderamente democrática.

10․ Este rápido análisis muestra que el debate entre laicistas y cristianos no es un debate banal, sino que afecta a graves cuestiones de antropología, como la concepción de la libertad, el origen de los principios morales y en último lugar la existencia o no existencia de un Principio superior, que se hace presente en la historia humana, y que es a la vez autor de la vida y fun damento de la libertad y de la conciencia del hombre. Esto es precisamente lo que los cristianos reconocemos, con una inmensa gratitud, en Jesucristo, aceptado y adorado como Hijo de Dios hecho hombre, muerto y resucitado, Señor y Salvador del mundo y de la historia. A pesar de todo, los católicos pensamos que laicos o laicistas y católicos podemos convivir pacíficamente, como podemos también convivir fieles de distintas religiones, a partir del respeto a los derechos y obligaciones fundamentales derivados del reconøci miento del valor absoluto de la persona en una sociedad de hombres libres. Esta convivencia requiere un conjunto de convicciones comunes respeta das por todos, clarificado y enriquecido mediante el diálogo constante, sin necesidad de excluir las ideas religiosas del patrimonio cultural y social de la sociedad en la cual estamos todos integrados. Los ciudadanos católicos podemos decir a un gobierno realmente laico: déjennos ser católicos con todas las consecuencias, más todavía, ayúdennos a ser buenos católicos, porque de nuestra catolicidad nacen para nosotros los fundamentos de una sólida ciudadanía, abierta y sincera, que estamos dispuestos a compartir con los demás grupos, en un esfuerzo constante por construir y actualizar un patrimonio común respetuoso con las convicciones de todos.

11‥ En resumen, el Manifiesto con el que los socialistas han querido con memorar el XXVIII aniversario de la Constitución nos ofrece la posibilidad de un diálogo riguroso y sereno. Por el momento, con los debidos respetos, no me parece un texto bien elaborado, contiene confusiones importantes y esconde una concepción de la vida política injusta con la religión y excesivamente autoritaria. Un texto, además, que, con apariencias laudatorias 
desplaza el valor y el verdadero sentido de la Constitución. Me gustaría que alguien me convenciera de lo contrario.

\section{Documento propuesta de Cristianos Socialistas del PSOE}

\section{Pacto por una laicidad incluyente ${ }^{2}$}

Madrid, 7 de febrero de 2007.

\section{(1) Libertad religiosa y Democracia}

Las conquistas a favor de los derechos humanos y las libertadesúblicas, entre ellas de forma primera la libertad religiosa; también el establecimiento del imperio de la ley, el gobierno de los hombres y la igualdad de todos los ciudadanos ante la ley, en definitiva el Estado democr ático, social y de derecho han sido una tarea compartida por actores diversos inspirados en matrices tanto religiosas como laicas. La historia lo acredita. Podemos citar entre los religiosos a Ockam, Marsilio de Padua, Moro, de las Casas, de Vito ria, Erasmo, Kant, Montalambert, Ozanam, Hardie, De Gasperi, Mounier,... y, más allá de Europa, en el siglo XX otros como Gandhi o Luther King. Las creencias religiosas no §́lo no son incompatibles con la democracia sino que han sido una de sus más importantes fuentes de inspiración como lo afirma el preámbulo de la Constitución Europea. El Consejo de Europa argumenta además los beneficios mutuos afirmando que "la democracia proporciona el mejor marco a la libertad de conciencia, al ejercicio de la fe y al pluralismo de las religiones" y, por su parte, "la religón, por su compromiso moral yético, por los valores que ella defiende, por su sentido crítico y por su expresión cultural puede ser un complemento valioso de la sociedad democrática"3.

Las democracias necesitan de una ciudadan ía activa y estamos convencidos de que las confesiones religiosas son expresión e instrumento de una ciudadanía participativa y solidaria.

2 "A finales del 2006 se suscitó un debate necesario e interesante sobre la laicidad con motivo de la Declaración del diputado D. Álvaro Cuesta, Secretario de Libertades Públicas de la Comisión Ejecutiva socialista, con motivo de la celebración por el PSOE del Día de la Cons titución (Málaga, 5-XII-2006). Esa declaración estimuló una lectura crítica del arzobispo de Pamplona D. Fernando Sebastián (10-XII-2006), con numerosos argumentos y sobre todo con una invitación al diálogo al que queremos contribuir desde nuestro compromiso como cristianos socialistas del PSOE". (Preliminar del propio documento, que hemos incluido a pie de página. Nota de la redacción). 
En nuestra historia reciente, tal encuentro entre Religin y Democracia ha sido particularmente manifiesto en la lucha antifranquista, en el proceso de la transición y consolidación democrática y particularmente en la elaboracón de la Constitución Española.

\section{(2) Constitución: separación y cooperación}

Nuestra más alta norma democr ática declara en el art. 16.1 la libertad ideológica, religiosa y de culto de los individuos y las comunidades religiosas. Es lo propio de un Estado democrático y de derecho en sociedades plurales y avanzadas. En consecuencia con ello establece en el art. 16.3 que ninguna confesión tendrá carácter estatal. Este artículo implica la "neutralidad" del Estado ante las diferentes posiciones que en materia religiosa expresan los ciudadanos, algo que pertenece a cada cual en el ejercicio de la libertad de conciencia (STC ${ }^{4}$ 340/1993). El Estado debe así respetar y proteger la libertad religiosa e ideológica de todos los ciudadanos, de los creyentes y de los no creyentes, evitando "cualquier tipo de confusión entre fines religiosos y estatales” (STC 177/1996).

Sin embargo la separación entre Estado y religión, necesaria en un sistema democrático, no significa indiferencia o pasiva neutralidad del Estado hacia el hecho religioso. Ni siquiera se agota en la protecci ón del derecho a la libertad religiosa (STC 46/2001). No al menos en el caso de la Consti tución Española que establece expresamente como principio normativo la cooperación con la Iglesia cat ólica y las dem ás confesiones religiosas. Es una relación de cooperación fundada en el reconocimiento de las creencias religiosas de la sociedad española, antes que por sus efectos sociales, por cuanto son expresǿn y ejercicio de un derecho fundamental (16.3). El principio constitucional respecto a la religión es la obligada promoción por parte de los poderes públicos de una participación cooperativa y demócrata de las personas y comunidades religiosas en la vida pública, sin que ello suponga que ninguna religión sea estatal ni que nadie se vea obligado a declarar su posición en materia religiosa (16.2).

Estos principios constitucionales no son compatibles con una pol ítica de laicidad que obligue a la privatizaci ón individualista de la religi ón, la

3 Recomendación del Consejo de Europa nº 1.396 sobre Democracia y Religión.

4 STC: a partir de ahora, Sentencia del Tribunal Constitucional. 
desatención pública de los asuntos religiosos, la no cooperacín activa con la Iglesia católica y las otras confesiones religiosas, o la indiferencia ante la discriminación en el ejercicio de otras formas de libertad religiosa. La Cons titución impide que ninguna religión sea considerada estatal pero defiende expresamente la presencia, actividad y responsabilidad de las comunidades religiosas en la vida p ública en cuanto ejercicio de la dimensi ón colectiva de los derechos de libertad de creencia de los ciudadanos y ciudadanas. El único límite a la libertad de los individuos y las comunidades religiosas desde el punto de vista de su manifestaci ón pública es el mantenimiento del orden público.

Es preciso dejar constancia de que la palabra laicidad ni ninguno de sus derivados -laico, laica, laicista, etc.- constan en ning ún artículo de la Constitución Española de 1978. En este sentido no es una conceptualizacôn primigeniamente constitucional, como tampoco la aconfesionalidad.

\section{(3) Laicidad, principio de convivencia}

Las interpretaciones de los principios constitucionales antedichos han sido diversas. El Tribunal Constitucional considera que el articulado constitucional introduce una idea de "aconfesionalidad o laicidad positiva" (STC 46/2001). Así desde un punto de vista constitucional, laicidad nunca puede significar privatización, irreligiosidad o neutralidad pasiva sino libertad, proteccón y cooperación; y en negativo no estatalidad, no discriminación.

La plasticidad de la noción de laicidad puede servir a pretensiones poco acordes con el sentido del texto constitucional. Bajo una interprémciparcial y sesgada del principio de laicidad hay quienes justifican la prohibión de la realización de procesiones de semana santa en nuestro ṕsa la eliminacón de belenes navideños en las escuelas, la expulsión de las enseñanzas regladas de religión con optatividad en la escuela pública o que se llegue a anular la colaboración o ayuda econ ómica del Estado en la financiaci ón de las confesiones religiosas. Estas pretensiones contradicen el esp íritu y letra de la Constitución y el sentir mayoritario de los españoles. Son reivindicaciones legítimas pero no se pueden defender en nombre del pacto constitucional.

La alianza constitucional de 1978 supuso un aprendizaje por parte de todos, una refundación no sólo de la democracia en España sino de muchas instituciones. La laicidad constitucional es aquella que fue capaz de incluir a todos en una comunidad política en la que todos pusieron lo mejor de sí; 
en la cual creyentes y no creyentes unieron su voluntad y generosidad para construir una sociedad mejor. No hemos dejado de profundizar en ella y la presencia de más minorías religiosas, creciente por los flujos migratorios, va a enriquecer esa suma.

La libertad religiosa para todos ha necesitado de la contribuci ón del pensamiento y el movimiento por un Estado laico que se ha abierto camino no sin resistencias de las religiones establecidas, en nuestro caso la Iglesia católica. He ahí contribuciones que hoy todos reconocemos: la libertad de culto, la secularización de los cementerios, el matrimonio y divorcio civiles, la escuela p ública, entre otras. En la modernidad, el propio cristianismo que ha inspirado desde sus orígenes una concepción secularizada de la autoridad política, ha podido mejorar y aquilatar con esas interpelaciones su concepción de las relaciones entre religión y política. La más destacable es la promoción por la Iglesia católica del concepto de laicidad. Benedicto XVI el 9 de diciembre de 2006 ha recordado que "todos los creyentes, y de modo especial los creyentes en Cristo, tienen el deber de contribuir a elaborar un concepto de laicidad basado en la legítima autonomía de las realidades terrenas, entendiendo con esta expresión -como afirma el concilio Vaticano II- que las cosas creadas y las sociedades mismas gozan de leyes y valores propios que el hombre ha de descubrir, aplicar y ordenar paulatinamente "5. Pero como dice el propio papa ha de ser una "sana laicidad" lo que "implica que el Estado no considere la reliğin como un simple sentimiento individual, que se podría confinar al ámbito privado. Al contrario, la religi ón, al estar organizada también en estructuras visibles, como sucede con la Iglesia, se ha de reconocer como presencia comunitaria pública" 6 .

El calado de los desafíos de nuestro mundo nos indican que no estamos en tiempo de restar para dividir sino de sumar para multiplicar el progreso: nadie sobra y queremos insistir en el esp íritu de di álogo entre creyentes y no creyentes, no desde la perspectiva de los derechos y las identidades sino de la convivencia para la búsqueda común del bien. Es en eseánimo de diálogo, en ese espíritu de puentes, donde creemos que es posible conciliar lo que está enfrentado.

5 Constitución pastoral Gaudium et spes (1965), n. 36

6 Benedicto XVI, Discurso en el 56ª Congreso de la Unión de Juristas Católicos Italianos, Roma, 9-XII-2006. 


\section{(4) Ni socialismo ni religión son fundamentalismo}

Queremos manifestar que el socialismo espãol no hace una equivalencia entre religión y fundamentalismo. Tampoco ser ía justo deslegitimar el so cialismo por los momentos históricos en que ha despreciado la democracia o que ha caído en fundamentalismos doctrinarios contrarios a los más elementales derechos humanos. Religiones y socialismos aborrecemos fundamentalismos hechos en nuestro nombre o practicados por nosotros mismos en determinados momentos históricos. Cualquier tipo de fundamentalismo, sea religioso o político, es incompatible con la libertad y la convivencia en nuestras sociedades plurales. El antídoto ante el fundamentalismo político o religioso es más democracia constitucional.

Tampoco el socialismo puede permitir que se haga una equivalencia entre migración y fundamentalismo. Sabemos bien cómo la religión da soporte y promueve a cientos de miles de inmigrantes en nuestro pa ís ayudándoles a encontrar sentido, salir adelante e integrarse en nuestra sociedad. La existencia de algunos reducidos grupos integristas no arroja una sombra de sospecha sobre todos ellos. Por el contrario, la praxis que finalmente ha predominado en el gobierno socialista de José Luis Rodríguez Zapatero ha tendido a incorporar esa idea constitucional de laicidad cooperativa. Su política de asuntos religiosos ha hecho suyo el lema Pluralismo y Convivencia, tal como se ha denominado la Fundaci ón que para cooperar con las minor ías religiosas ha puesto eficazmente en marcha la Direcci ón de Asuntos Religiosos del Ministerio de Justicia, en aras a superar una grave discriminación histórica.

El socialismo no s ólo no quiere estar enfrentado a las confesiones reli giosas sino que quiere fomentar las convergencias: he ah í la emblemática propuesta de alianza de civilizaciones y su esfuerzo por separar religi ón y fundamentalismo: "es imprescindible reconocer que ninguna de las re ligiones del mundo condona ni aprueba la matanza de inocentes. Todas promueven la idea de la compasión, la justicia y el respeto a la dignidad de la vida" 7 . El socialismo en Europa y en la Internacional Socialista estima la afinidad existente entre los valores socialistas de emancipación e igualdad y los del profetismo religioso como la justicia y la solidaridad, que habitan en las tradiciones judeo-cristianas e islámica. En el desafío que representa

7 Alianza de Civilizaciones. Informe del Grupo de Alto Nivel , 13 de noviembre de 2006, n. 3.11 . 
la inmigración en Espa ña, confiamos y esperamos mucho de la actuaci ón positiva y efectiva de las distintas confesiones religiosas en beneficio de la integración, la solidaridad y la cultura democrática.

\section{(5) Leyes y criterios morales}

Se han suscitado en distintos momentos de las últimas décadas intensos debates respecto a algunos temas especialmente problem áticos para una convivencia plural y en los que las diferentes confesiones religiosas tienen mucho que decir, de un modo particular la religón católica, históricamente mayoritaria en nuestro pa ís. Temas como las asignaturas de Religi ón o de Educación para la Ciudadańa, cuestiones como el matrimonio entre personas del mismo sexo, el aborto o asuntos relativamente nuevos para nosotros como la eutanasia constituyen o pueden constituir puntos de conflicto entre las diferentes confesiones religiosas y los poderes polticos gobernantes en cada momento.

A este respecto, compartimos que los criterios morales que han de orientar la elaboración de los preceptos legales que regulan la convivencia no tienen por qué corresponderse obligatoriamente con la doctrina de una religión. El pluralismo ético y cultural es un dato correlativo a la sociedad libre y democrática. Sigue siendo un desafío necesario construir un marco de valores compartidos y de derechos humanos que inspiren las leyes. No hay un marco objetivo dado para siempre. Los diferentes poderes del Estado elegidos democráticamente, según su competencia espeófica, son los encar gados de establecer e interpretar el orden legislativo y dirimir los posibles conflictos de interpretación a que puede dar lugar su aplicaóin en cada caso concreto. Las diferentes confesiones religiosas pueden y deben influir en la propuesta de valores y en la conformacôn de la voluntad social. Tienen todo el derecho a ello. También podrán oponerse, objetar e impugnar mediante los diferentes medios privados o públicos establecidos al efecto (políticos, de opinión y manifestación, jurídicos, etc.), todas aquellas decisiones con las que no estén de acuerdo. Como ha dicho J. L. Rodiguez Zapatero las iglesias tienen un "derecho total" a discutir y a criticar las decisiones del poder, pero "lo que no tienen derecho es a hacer leyes e imponerlas" Consideramos que

8 “Diálogo sobre la Laicidad”, Entrevista de Paolo Flores D`Arcais a José Luis Rodríguez Za patero en Micromega 2 de marzo de 2006. 
los católicos estamos obligados como cualquier otro ciudadano a respetar y acatar las leyes democráticamente establecidas o también a sobrepasarlas desde una ética de máximos. Como dice la Carta a Diogneto sobre el testimonio de los cristianos del siglo II, los cristianos "respetan la leyes y con su vida las sobrepasan".

La Constitución de 1978, fruto de un amplio consenso democr ático, es la referencia b ásica de nuestro ordenamiento jur ídico y su aplicaci ón es competencia de los poderes p úblicos legítimamente establecidos. De un conflicto de valores no se desprende autom áticamente la inmoralidad de una ley ya que existen tambi én otras perspectivas diferentes cargadas de moralidad. Hay situaciones de excepci ón en que la ley no se ajusta a una moral como la cristiana. Es justo defender una perspectiva ética propia, en este caso católica, e incluso la objeción de conciencia. La libertad espiritual ante el poder injusto ha sido germen de nuestra democracia moderna frente al absolutismo, antes, el fascismo y el colectivismo despés. Sin embargo tal recurso no puede ser la vía para imponer legalmente una perspectiva ética específica a la sociedad. Menos justificable án es la recurrida acusación de ilegitimidad a quienes representan y ejercen el poder legislativo y ejecutivo desde una argumentación iusnaturalista, basada en la construcci ón social de una determinada ley natural.

No se pueden dirimir los conflictos de valores negando la legitimidad para intervenir al otro, excluyendo en definitiva al opuesto, en unos casos al Gobierno, en otros a las Iglesias el papel que a cada cual corresponde en la vida política. En cualquier caso seńa deseable llegar a una situación en la cual lo que nos interesara ṕblicamente sea el concurso de todos en aquellos aspectos especialmente conflictivos de cara a implantar una convivencia justa y pacífica. En este sentido, estamos convencidos, en concreto, de que tanto la asignatura de Educaci ón para la Ciudadanía como las Enseñanzas de la Religión, bien planteadas, pueden contribuir a formar ciudadanos par tidarios de una laicidad inclusiva e incluyente, identificados con los valores básicos de nuestra Constituci ón y conscientes de la contribuci ón positiva de las diferentes religiones al bien comín. Rechazamos expresamente tanto los planteamientos excluyentes de las ense ñanzas de la religi ón como las propuestas de desobediencia a educación para la ciudadanía. 


\section{(6) Constitución de 1978 y de 1931}

En relación con el reciente debate sobre nuestro pasado m ás reciente, coincidimos con el sentir humanitario general del socialismo español en la necesaria rehabilitación de la memoria histórica de las víctimas, la eliminación de agravios simbólicos que puedan sentir las v́ctimas y las medidas de reconciliación de nuestro país con las víctimas de la República, de la guerra civil y el franquismo. A ñadiríamos que la propia Iglesia cat ólica española debería aprovechar la actualidad de la memoria hist órica para hacer una revisión crítica de su posicionamiento en tales momentos hisøricos. Lo que no consideramos prudente ni justo es idealizar la Constituớn de 1931. Junto a sus innegables avances como la soberanía popular, el sufragio femenino o la descentralización del Estado, asumí graves violaciones de los derechos y libertades en materia religiosa. La doctrina constitucional supuso un avance en la libertad de culto y la separaci ón entre Estado e Iglesia cat ólica, pero varios enunciados de los artículos 26 y 27 atentaban gravemente contra las personas e instituciones religiosas, como la prohibión de la enseñanza a las congregaciones religiosas o la disolución de los jesuitas. Cuando una determinada acepción de la laicidad esconde la intención de eliminar la religión o reprimirla a la esfera privada individual se va por un camino contrario a la democracia y las libertades, aunque pueda pensarse lo contrario. No ayúdłar a la defensa de los derechos humanos que se sintiera eh́smínimo asomo de añoranza del paradigma constitucional republicano en materia de religǿn.

\section{(7) La laicidad como llamada al diálogo y al encuentro}

Desde Cristianos Socialistas somos conscientes de que la estrategia de un laicismo anticlerical ha podido ser muy interiorizada por personas de un partido que ha pasado muchas d écadas en el exilio sufriendo mientras en España se asentaba el nacional-catolicismo. Hacer evolucionar el paradig ma y la identidad corporativa en una instituci ón como un partido siempre supone largos tiempos de transición. Este proceso tuvo un hito inicial en la Declaración sobre la Iglesiadel PSOE en el XXIII Congreso en Toulouse en 1967 donde se afirmó que "socialismo y cristianismo en tanto religión de amor al prójimo son absolutamente conciliables". Tambi én sabemos que un signi ficativo sector del mundo católico está en nuestro país todavía demasiado encastillado en prejuicios histricos contra el socialismo, al que percibe como adversario ideológico y agente de una cultura laicista. Creemos que esto no se soluciona sólo con la deliberación ideológica sino con la confianza de la 
convivencia. Precisamente, el imperativo de la laicidad nos tiene que alentar al encuentro frecuente, al diálogo sincero, a la colaboración. Seamos laicos: tendamos puentes y no ensanchemos las brechas. El alf́simo porcentaje de católicos que votan al partido socialista es una poderosa prueba de laicidad incluyente ya presente hoy en la vida cotidiana de los ciudadanos.

\section{(8) Pacto por una Laicidad Incluyente}

Hemos de ponernos a sentar las bases de unPacto por una Laicidad Inclut yente sobre tres vectores:

1. El desarrollo activo de la laicidad del Estado, de las instituciones públicas y de las leyes ante restos de confesionalismo; algo que debe hacerse no frente al factor religioso sino desde la inclusión, la cooperación y el reconocimiento de la aportación de las creencias religiosas a la construcción de una sociedad justa, a la deliberación pública y a la convivencia democrática.

2. La construcción de un marco ético cívico compartido que debe sostenerse y enriquecerse no sólo desde matrices laicas o sólo religiosas, sino desde la contribución y el diálogo en un marco de laicidad.

3. La acción positiva para superar la discriminación del conjunto de las confesiones religiosas no católicas a destacar la protestante, la judía y la musulmana, lo cual habrá de suponer la renuncia a privilegios por parte de los católicos. Sin embargo esta acción no debe hacerse para difuminar el catolicismo como una entre otras sino desde el recono cimiento de la singularidad histórica, cultural y pública de la Iglesia católica en un país como Españ a, algo expresamente reconocido por la propia Constitución.

Es hora de debatir y madurar el papel que otorgamos a las creencias reli giosas en la sociedad española. Es justo y necesario que las organizaciones políticas, sindicales y sociales asuman en su cultura corporativa la libertad y cooperación religiosas. Donde religión y socialismo tienen unas sanas rela ciones de cooperación, el progreso se multiplica y crea sentido y solidaridad, especialmente allí donde la justicia y la vida están más amenazadas. 